OPEN ACCESS

Edited by:

Mahmut Tör,

University of Worcester, UK

Reviewed by:

Hikmet Budak

Montana State University, USA

Ömür Baysal,

Muğla University, Turkey

*Correspondence:

Guoqiang Fan

zlxx64@126.com

Specialty section:

This article was submitted to

Plant Microbe Interactions,

a section of the journal

Frontiers in Plant Science

Received: 16 September 2016

Accepted: 27 February 2017

Published: 10 March 2017

Citation:

Cao X, Fan G, Dong Y, Zhao Z,

Deng M, Wang Z and Liu W (2017)

Proteome Profiling of Paulownia

Seedlings Infected with Phytoplasma.

Front. Plant Sci. 8:342.

doi: 10.3389/fpls.2017.00342

\section{Proteome Profiling of Paulownia Seedlings Infected with Phytoplasma}

\author{
Xibing Cao ${ }^{1,2}$, Guoqiang Fan ${ }^{1,2 *}$, Yanpeng Dong ${ }^{1,2}$, Zhenli Zhao ${ }^{1,2}$, Minjie Deng ${ }^{1,2}$, \\ Zhe Wang ${ }^{1}$ and Wenshan Liu ${ }^{1,2}$ \\ ${ }^{1}$ Institute of Paulownia, Henan Agricultural University, Zhengzhou, China, ${ }^{2}$ College of Forestry, Henan Agricultural University, \\ Zhengzhou, China
}

Phytoplasma is an insect-transmitted pathogen that causes witches' broom disease in many plants. Paulownia witches' broom is one of the most destructive diseases threatening Paulownia production. The molecular mechanisms associated with this disease have been investigated by transcriptome sequencing, but changes in protein abundance have not been investigated with isobaric tags for relative and absolute quantitation. Previous results have shown that methyl methane sulfonate (MMS) can help Paulownia seedlings recover from the symptoms of witches' broom and reinstate a healthy morphology. In this study, a transcriptomic-assisted proteomic technique was used to analyze the protein changes in phytoplasma-infected Paulownia tomentosa seedlings, phytoplasma-infected seedlings treated with 20 and $60 \mathrm{mg} \cdot \mathrm{L}^{-1} \mathrm{MMS}$, and healthy seedlings. A total of 2,051 proteins were obtained, 879 of which were found to be differentially abundant in pairwise comparisons between the sample groups. Among the differentially abundant proteins, 43 were related to Paulownia witches' broom disease and many of them were annotated to be involved in photosynthesis, expression of dwarf symptom, energy production, and cell signal pathways.

\section{Keywords: Paulownia tomentosa, witches' broom, phytoplasma, transcriptome, iTRAQ, LC-MS/MS}

\section{INTRODUCTION}

Paulownia, a fast-growing greening tree species, has many sought-after characteristics, including lightweight wood, high biomass production, and vigorous resprouting ability, which make them ideal environment protection trees. However, Paulownia is susceptible to a phytoplasma that causes Paulownia witches' broom (PaWB) disease, which gradually reduces biomass production (Doi et al., 1967). PaWB disease is usually characterized by stunted growth, witches' brooms, and phyllody, followed by dieback of branches and phloem necrosis (Namba, 2002).

Numerous studies have been carried out on Paulownia phytoplasma and the interaction of host with pathogen, and some advances at the physiological and chemical morphological, genetic, transcriptional, and epigenetic levels have been made (Doi et al., 1967; Fan and Jiang, 1997; Fan et al., 2007; Lin et al., 2009; Mou et al., 2013). The infecting phytoplasma lacks a cell wall and is bound only by a triple-layered unit membrane, which makes it difficult to culture in vitro (Doi et al., 1967). Although high-throughput sequencing and epigenetic technologies have been used to investigate the genes, microRNAs, and inherent metabolic pathways related to PaWB disease (Liu et al., 2013; Cao et al., 2014a,b; Fan et al., 2014, 2015a,b,c; Niu et al., 2016) however, understanding of the whole mechanisms of Paulownia-phytoplasma interactions is still lacking. 
Proteins play important roles in catalyzing almost all chemical reactions, including those involved in plant growth and development, metabolism, and resisting pathogen invasion (Luge et al., 2014). Protein changes that occur in response to the interaction between Paulownia and phytoplasma have been studied using two-dimensional polyacrylamide gel electrophoresis (2D-PAGE; Fan et al., 2003); however, it is difficult to separate low abundance proteins and hydrophobic proteins using this technique (Molloy and Witzmann, 2002; Baggerman et al., 2005). Thus, 2D-PAGE cannot be used to characterize the profiles of all the proteins in cells or tissues; furthermore, the results are often difficult to reproduce. To help overcome some of the disadvantages of 2D-PAGE, several proteomic quantitative methods have been developed (Lodha et al., 2013). One such method is iTRAQ, which involves isobaric tagging of peptides for protein quantitation using mass spectrometry. iTRAQ can be used to identify and quantify hundreds of proteins in up to eight samples at one time with high sensitivity and accuracy (Fan et al., 2011; Wang B. et al., 2015), and has been successfully applied to detect changes in protein abundances in plants with pathogen infections (Taheri et al., 2011; Monavarfeshani et al., 2013; Dadakova et al., 2015).

Previously, we have shown that the symptoms of PaWB disease were reversed by treatment with a suitable concentration of methyl methane sulfonate (MMS) and that the phytoplasma was not detected in the recovered plants (Cao et al., 2014a; Fan et al., 2015a). In this study, we used iTRAQ to investigate protein changes in four groups of Paulownia tomentosa seedlings: healthy seedlings, phytoplasma-infected seedlings, and phytoplasmainfected seedlings treated with 20 or $60 \mathrm{mg} \cdot \mathrm{L}^{-1} \mathrm{MMS}$. Proteins associated with PaWB disease were identified by searching against transcriptome sequences from the same samples. We identified a number of proteins that showed changes in abundance after infection by the PaWB phytoplasma, which may help in understanding the mechanisms associated with PaWB disease.

\section{MATERIALS AND METHODS}

\section{Plant Material and Treatment}

All samples in this study were tissue culture seedlings, healthy $P$. tomentosa seedlings (HP) and P. tomentosa seedlings infected with PaWB phytoplasma (PIP), both of them were obtained from the Institute of Paulownia. These seedlings were cultured for 30 days on 1/2 MS medium before being clipped (Murashige and Skoog, 1962). After clipping, the terminal buds of $1.5-\mathrm{cm}$ PIP were transferred into $100-\mathrm{mL}$ triangular flasks containing $20 \mathrm{ml} \mathrm{1/2}$ MS culture medium supplemented with 0 , 20, or $60 \mathrm{mg} \cdot \mathrm{L}^{-1}$ MMS (PIP, PIP-20, and PIP-60 respectively). The terminal buds of $1.5-\mathrm{cm}$ HP were transferred into the same medium without MMS as the control. All the seedlings were cultured in a darkroom at $20^{\circ} \mathrm{C}$ for 5 days. After that, they were cultured at $25 \pm 2{ }^{\circ} \mathrm{C}$ under $130 \mu \mathrm{mol} \cdot \mathrm{m}^{-2} \mathrm{~s}^{-1}$ light intensity with a $16 / 8 \mathrm{~h}$ light /dark photoperiod for 25 days. Then, the terminal buds of $1.5-\mathrm{cm}$ seedlings in the four treatment groups were sheared, immediately frozen in liquid nitrogen, and stored at $-80^{\circ} \mathrm{C}$. For each treatment, 60 terminal buds were planted in 20 flasks. Each treatment was performed in triplicate.

\section{Extraction of Protein from Paulownia}

The four samples (HP, PIP, PIP-20, and PIP-60) were ground to powder in liquid nitrogen, then these different powder were added the moderate lysis buffer with $1 \mathrm{mM}$ PMSF and $2 \mathrm{mM}$ EDTA, the details of the protein extraction method was described as Tang et al. (2016).

\section{iTRAQ Labeling and Strong Cation Exchange Fractionation}

To label the peptides obtained from the HP, PIP, PIP-20, and PIP-60 samples with iTRAQ reagent, $100 \mu \mathrm{g}$ total protein from each sample solution was digested with Trypsin Gold (Promega, Madison, WI, USA). The peptides in the four samples were labeled with isobaric tags, the details method of iTRAQlabeled according to the method of Meng et al. (2014). The labeled peptide mixtures were pooled and dried by vacuum centrifugation. Strong cation exchange (SCX) chromatography was performed with a LC-20AB HPLC Pump system (Shimadzu, Kyoto, Japan). The labeled peptide mixture contained proteins extracted from the PIP, PIP-20, PIP-60, and HP samples, including two technical replicates of isotopic labeling. Each biological replicate consisted of 12 terminal buds of the same stage from four different samples.

\section{LC-MS/MS Analysis}

The labeled peptide mixture was firstly resuspended and then the supernatant was loaded on a LC-20AD nano HPLC system (Shimadzu), then the data acquisition was performed with a TripleTOF 5600 System (AB sciex, concord, ON, Canada) fitted with a Nanospray III source (AB sciex) and a pulled quartz tip as the emitter (New Objectives, Woburn, MA). The mass spectrometer was operated with a RP of $\geq 30,000$ full-width half-maximum for time-of-flight mass spectrometry scans. The method of the peptides were separated according to Qiao et al. (2012).

\section{Data Analysis}

Raw data files were firstly converted into Mascot generic format files using Proteome Discoverer 1.2 software (Thermo Fisher Scientific, Bremen, Germany), then these data were matched against the transcriptome database containing 105,812 all-unigene sequences (Fan et al., 2015a,b). For protein identification, to reduce the probability of false peptide identification, only peptides at the $95 \%$ confidence interval, as defined by Mascot probability analysis, greater than "identity" were considered as identified, and each confident protein involved at least one unique peptide. For protein quantitation, it was required that a protein contained at least two unique spectra.

To further identify the functions of the identified proteins, the Blast2GO program was run against the NCBI non-redundant protein sequence database to assign them Gene Ontology (GO) terms. The Kyoto Encyclopedia of Genes and Genomes (KEGG) and the Clusters of Orthologous Groups (COG) databases were used to classify and group the identified proteins. Quantitative 
protein ratios were weighted and normalized by the median ratio in Mascot. Proteins with a fold change $\geq 1.2$ and $p<0.05$ were determined as differentially abundant proteins.

\section{Correlation Analysis of the Transcriptome and Proteome Data}

In this section, the correlation analysis of the transcriptome and proteome data was carried out. Firstly, the proteins identified by iTRAQ were matched to 105,812 unigene sequences of the transcriptome. After that, the proteins which have homologs in the transcritome were screened out. Then we calculated the number of the correlated protein in four different comparisons, including the PIP vs. PIP-20 comparison, PIP-20 vs. PIP60 comparison, HP vs. PIP-60 comparison and HP vs. PIP comparison, and the correlated proteins can be considered as the identified proteins which have been expressed at the transcription level. Subsequently, the quantitative analysis of the correlated proteins was performed, and the criterion of the quantitation protein is the unique peptide $\geq 2$. According to the results of the quantitative analysis, we further picked out the differentially expressed proteins (fold change $\geq 1.2$ and $p<$ 0.05 ) in different comparisons. At last, the number of the genes that corresponding to the correlated proteins and the number of differential expressed proteins were figured out. The other important correlation analysis is to compare the abundance levels of the differentially expressed proteins and their corresponding genes from the transcriptome sequencing.

\section{Comparison Scheme of Proteins Associated with PaWB}

A comparison scheme of PaWB-related proteins was described by Liu et al. (2013). The proteins were searched against the NCBI non-redundant protein sequence database using the Blast2GO program to assign GO terms, and against the COG and KEGG databases to classify them to pathways and functional groups. To deeply analyze the function of PaWB-related proteins, protein BLAST (https://blast.ncbi.nlm.nih.gov/Blast.cgi) was used to confirm the function of these proteins, then the functional classification of them was performed.

\section{Quantitative Real-Time RT-PCR Analysis}

RNA samples from HP, PIP, PIP-20, and PIP-60 were extracted with Trizol (Sangon, Shanghai, China). First-strand cDNAs of the RNA samples were synthesized using an iScript cDNA synthesis kit (Bio-Rad, Hercules, CA, USA). From the transcriptome data (Fan et al., 2015a,b), we randomly chosen 12 unigene sequences that corresponded to the differentially abundant proteins for
qRT-PCR, primers for each of the unigenes were designed using PrimerPremier 5.0 software (PREMIER Biosoft International, Palo Alto, Calif). The results were analyzed using the $2^{-\Delta \Delta \mathrm{Ct}}$ method (Livak and Schmittgen, 2000). The expression level of each unigene was analyzed in three replicates. All the primers sequences used for the qRT-PCR are listed in Supplementary Table S1. Statistical analysis was performed using SPASS 19.0 (SPASS, Inc., Chicago, IL, USA).

\section{RESULTS}

\section{Identification of Basic Protein Information by iTRAQ Analysis}

We used an iTRAQ approach to analyze the total proteins in four P. tomentosa samples (HP, PIP, PIP-20, and PIP-60; Table 1). Protein homologs were identified against the transcriptome sequencing data from the same samples. We obtained 386,933 total spectra by combination analysis, and 21,948 of the spectra were matched using Mascot software. Among the 21,948 matched spectra, 17,811 were unique. The total number of detected proteins was 2,051 (Supplementary Table S2). The accuracy of the mass spectrometry was $<2 \mathrm{ppm}$, and the database search peptides matching error was below $0.05 \mathrm{Da}$. We carried out two biological replicates to identify the total proteins and found that 1,597 of the proteins were identified in repeat $1,1,657$ were identified in repeat 2, and 1,203 were common to the two sets (Figure 1). The producibility of the proteomic analysis showed that the results for the duplicates were of high quality (Figure 2), which indicated that the proteome results were reliable.

\section{Functional Classification of the Identified Proteins}

The functions of the 2,051 identified proteins were classified using COG. The proteins were classified into 23 COG subgroups (Figure 3), among which "general function prediction only," "post-translational modification, protein turnover, chaperones," and "energy production and conversion" were significantly enriched and contained the largest numbers of proteins, while "RNA processing and modification," "defense mechanisms," and "cell motility" contained the smallest numbers of proteins (Supplementary Table S3). The 2,051 proteins were also classified into the three GO categories: biological process, molecular function, and cellular component (Figure 4). Under biological process, "metabolic process" contained the largest number of proteins; under cellular component, "cell" and "cell part" contained the largest numbers of proteins; and

TABLE 1 | Statistic of protein identification.

\begin{tabular}{lccccc}
\hline Group name & Total spectra & Spectra & Unique spectra & Peptide & Unique peptide \\
\hline Repeat 1 & 182,895 & 10,381 & 8,500 & 3,773 & 3,324 \\
Repeat 2 & 204,038 & 11,567 & 9,311 & 3,986 & 3,460 \\
Combination & 386,933 & 21,948 & 17,811 & - & - \\
\hline
\end{tabular}

Repeat 1: the first repetition of protein identification. Repeat 2: the second repetition of protein identification. 


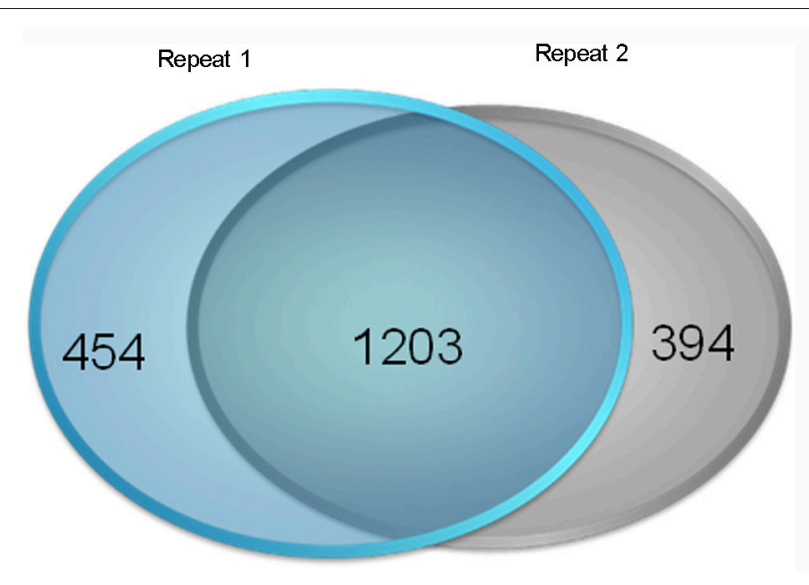

FIGURE 1 | Results of the reproducibility of protein identification. Repeat 1: the first repetition of protein identification. Repeat 2: the second repetition of protein identification.

under molecular function, "catalytic activity" contained the largest number of proteins (Supplementary Table S4). In the KEGG pathways analysis (Supplementary Table S5), the 2,051 proteins were mapped to 117 biological pathways of which "metabolic pathways," "biosynthesis of secondary metabolites," and "ribosome" were the most enriched metabolism pathways, while "linoleic acid metabolism," "monoterpenoid biosynthesis," and "circadian rhythm-plant" were the least enriched pathways. Based on these results, we concluded that most of the annotated proteins may affect metabolic processes, post-translational modification, protein turnover, chaperones, and catalytic activity.

\section{Analysis of Differentially Abundant Proteins between the Diseased and Recovered Seedlings}

Differentially abundant proteins (DAPs) were defined as proteins having a 95\% confidence level, $p<0.05$, and fold changed $>1.2$. According to these criteria, the abundance of 1,172 of the 2,051 proteins did not differ significantly in the PIP vs. HP, PIP-60 vs. PIP-20, PIP-20 vs. PIP, and PIP-60 vs. HP comparisons, while the abundance of 879 of the proteins changed significantly (Table 2). Among the 879 DAPs, 223 were identified in PIP vs. HP, 204 were identified in PIP-60 vs. PIP-20, 278 were identified in PIP-20 vs. PIP, and 174 were identified in PIP-60 vs. HP. Further analysis indicated that most of the DAPs were correlated to several metabolism pathways, namely biosynthesis of secondary metabolites, photosynthesis, carbon fixation in photosynthetic organisms, carotenoid biosynthesis, nitrogen metabolism, porphyrin, and chlorophyll metabolism, glyoxylate and dicarboxylate metabolism, pyrimidine metabolism, porphyrin, and chlorophyll metabolism, and plant-pathogen interaction.

\section{Correlation of Transcriptome and Proteome Data}

A correlation analysis of the transcriptome and proteome data was carried out, and the numerical relationships between the correlated proteins and the total proteins were calculated in the different comparisons. In the PIP vs. PIP-20 comparison, 2,050 proteins were correlated with the transcriptional data; among them, 1,046 proteins were quantitated and 278 of them were differentially abundant. In the PIP-20 vs. PIP-60 comparison, 2,048 proteins were correlated with the transcriptional data; among them 1,051 proteins were quantitated and 204 of them were differentially abundant. In the HP vs. PIP-60 comparison, 2,049 proteins were correlated with the transcriptional data; among them, 1,083 proteins were quantitated and 174 of them were differentially abundant. In the HP vs. PIP comparison, 1,073 proteins were quantitated and 223 of them were differentially abundant. All the numbers of these proteins corresponding genes were shown in Table 3.

Based on these results, we compared the abundance levels of the proteins and the expression levels of their corresponding genes. The following patterns were detected: (1) the same trend between the corresponding mRNA and protein levels; (2) the opposite trend between the corresponding mRNA and protein levels: (3) no change in protein levels, but changes in gene expression levels; (4) changes in protein levels, but no change in gene expression levels. These results show that the protein abundance level is not necessarily reflected in the expression level of the corresponding mRNA. Similar results have been reported in phytoplasma-infected Mexican lime (Monavarfeshani et al., 2013).

\section{Analysis of DAPs Related to PaWB}

According to the comparison scheme of PaWB-related proteins, a total of 43 DAPs were obtained that changed their abundance levels in response to phytoplasma infection (Table 4), then the function of 43 DAPs were further classified in the COG, GO, and KEGG databases. The DAPs were classified into $13 \mathrm{COG}$ categories (Supplementary Table S6), among which the three largest groups were "energy production and conversion," "posttranslational modification, protein turnover, chaperones," and "general function prediction only." The 43 DAPs were assigned 38 GO terms (Supplementary Table S7); 20 were under biological process, 11 were under cellular component, and five were under molecular function. In the KEGG pathway enrichment analysis, the 43 DAPs were mapped to 27 pathways (Supplementary Table S8), among which the two largest groups were "metabolic pathways" and "biosynthesis of secondary metabolites," while the two smallest groups were "plant-pathogen interaction" and "phenylpropanoid biosynthesis," indicating that changes in some metabolites may be important in the response of $P$. tomentosa seedlings to PaWB infection.

To confirm and dig out the function of the 43 DAPs, protein sequence BLAST (https://blast.ncbi.nlm.nih.gov/Blast.cgi) was used to confirm the functional of the 43 DAPs in other plant. The result showed 40 DAPs functions have been confirmed in other plants (Table 4). Of these proteins, six proteins were classified in the section named as post-translational modification, protein turnover, chaperones, such as, $20 \mathrm{~S}$ proteasome beta subunit, ubiquitin extension protein, subunit of chloroplasts chaperonin, peptidyl-Prolyl Isomerase, Co-chaperone GrpE family protein and fk506- and rapamycin-binding protein; 

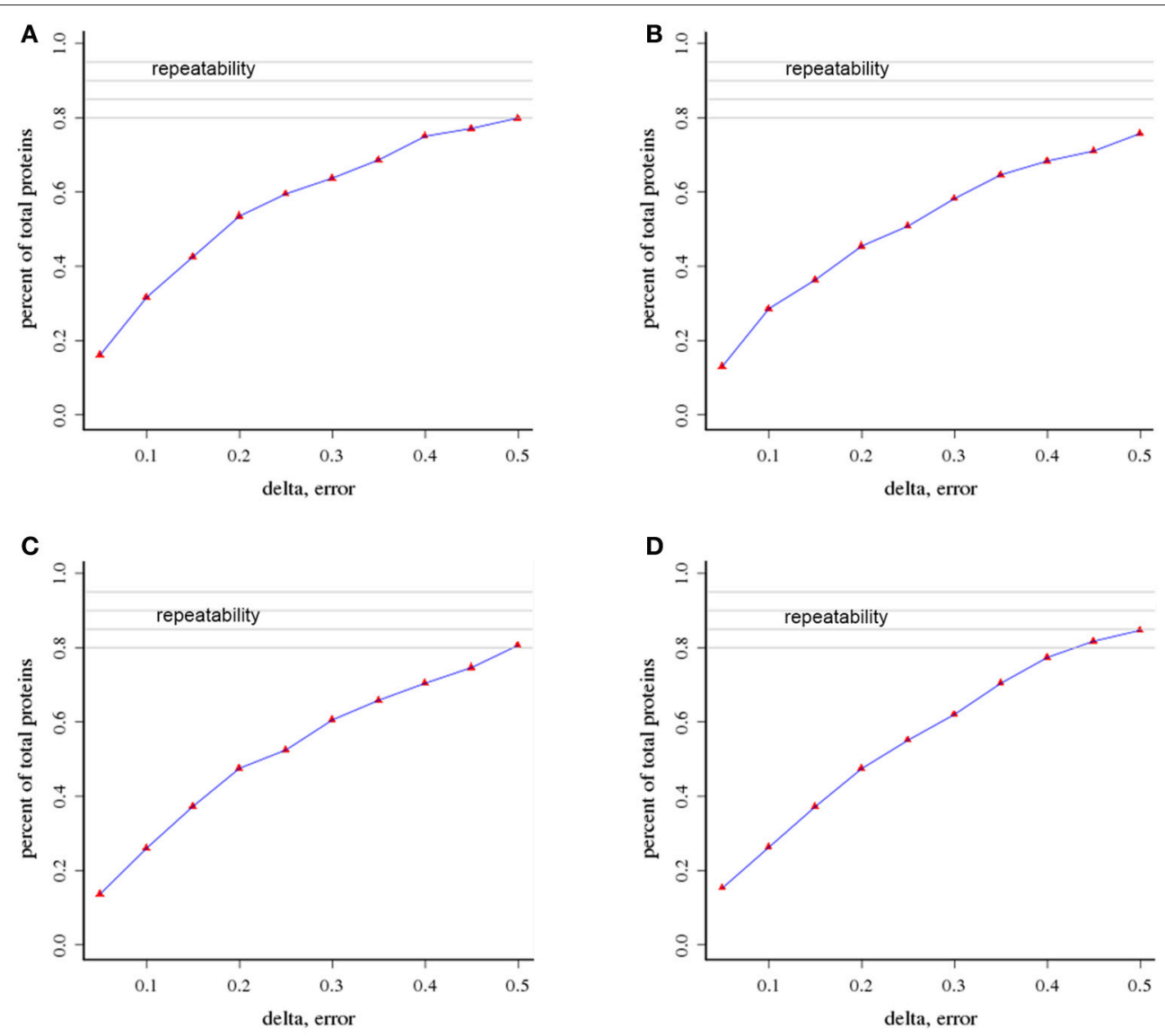

FIGURE 2 | Analysis of the repeatability of protein identification (A) HP vs. PIP; (B) HP vs. PIP-60 (C) PIP-20 vs. PIP-60; (D) PIP vs. PIP-20.

six proteins participated in photosynthesis pathway, including chloroplast thylakoid lumen protein (TLP), photosystem I subunit E-2 (PSI-E2), plastid-specific ribosomal protein 4 (PSRP4), the component of the light harvesting complex (LHCI) and alpha carbonic anhydrase (CA), and the subunit $\mathrm{E}$ of photosystem I (PSI-E2); three proteins were associated with energy metabolism pathway, such as ATP synthase gamma subunit, NADP-malic enzyme (NADP-ME), and the subunit of glyceraldehyde-3-phosphate dehydrogenase (GAPC); two $\mathrm{Ca}^{2+}$ binding protein involved in cell signal transduction pathways; five proteins, included aldo/keto reductase, cinnamyl-alcohol dehydrogenase, fasciclin-like arabinogalactan protein, germinlike protein, and pectin methylesterase took part in plant defense. In addition these DAPs with functions, 3 of PaWB-related proteins were annotated as unknown function, their function still need to verify.

\section{qRT-PCR Analysis}

To confirm the results of the transcriptome sequencing data, 12 gene sequences corresponding to PaWB-related proteins were selected randomly for the qRT-PCR assays (Figure 5). The results showed that the relative expressions of six of the 12 DAPrelated unigenes were significantly down-regulated in the process of the morphometric recovery, while five were significantly up-regulated. These 11 DAP-related expression patterns were consistent with the results of the iTRAQ LC-MS/MS analysis. For one of DAPs, no related mRNA expression was detected. This discrepancy may be attributed to post-transcriptional processing, post-translational processing and modification, or to different rates of degradation of mRNA and protein.

\section{DISCUSSION}

Information about the molecular basis of the Paulownia response to phytoplasma infection is still meager. For many years, our group has investigated the molecular mechanisms of $\mathrm{PaWB}$ and reported changes at the physiology, biochemistry, morphology, and molecular levels in the host Paulownia plants (Fan et al., 2003, 2014, 2015a,b,c; Liu et al., 2013; Cao et al., 2014a,b; Steinhorst and Kudla, 2014; Niu et al., 2016). We identified some PaWB-related genes and functionally classified them, detected changes in DNA methylation levels and patterns, and discovered some important proteins related to PaWB disease. Even so, many relevant aspects of this disease still need to be addressed. In this study, we adopted a transcriptomic-assisted proteomic approach to investigate protein changes associated with the 


\section{COG Function Classification of all_protein Sequence}

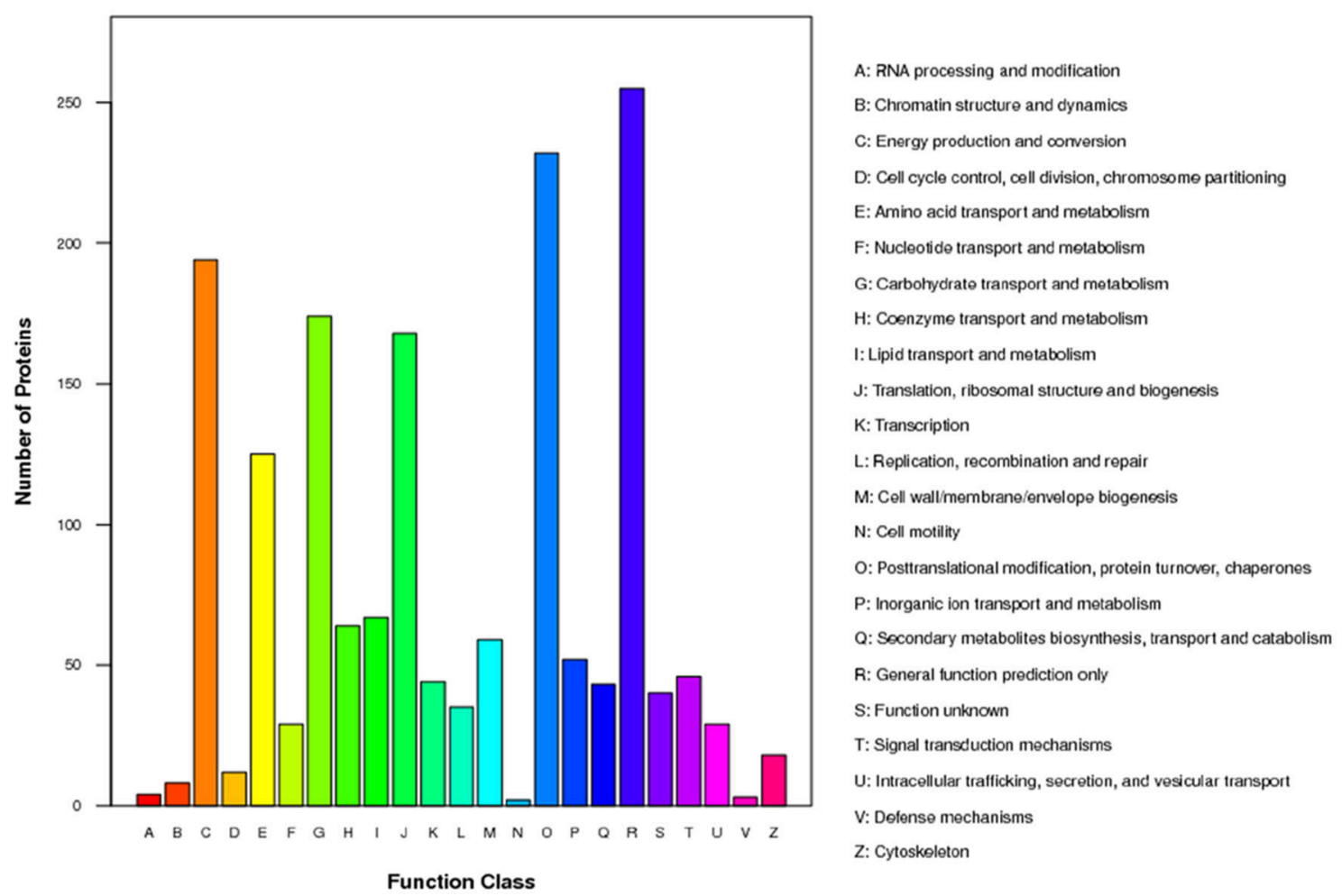

FIGURE 3 | COG classification of all protein.

interaction of $P$. tomentosa and phytoplasma. We obtained a total of 2,051 proteins by searches against the transcriptome data (Fan et al., 2015a,b). According to our previous scheme, the correlation analysis between the transcriptome and proteome data identified 43 DAPs potentially related to PaWB. These DAPs were predicted to be involved in photosynthesis, energy metabolism, lipid metabolism, the calvin cycle, glycolysis/ gluconeogenesis, epigenetic modification, plant resistance, and signal transduction.

\section{Phytoplasma Infection Decrease the Expression of Major Components of Photosynthesis}

The onset of the yellowish leaves symptom in phytoplasmainfected plants is one of the most obvious symptoms of witches' broom. This symptom is closely related to changes in photosynthesis, and many studies have reported that photosynthesis is arrested in phytoplasma-infected plants, as evidenced by a decrease in pigment molecules such as chlorophyll b levels soon after infection (Scarpari et al., 2005). Accordingly, phytoplasma infection leads to a reduction in the expression of genes that encode photosystem components, further suppressing photosynthesis (Ji et al., 2009; Margaria et al., 2012; Nejat et al., 2015). Similar results have been reported in the interaction of
Paulownia and phytoplasma, where several important protein components associated with photosynthesis were found to be significantly differentially abundant. These components include two proteins in photosystem I, six proteins in photosystem II, two proteins in light harvesting complex I, pyruvate kinase, and the pI6.8 24-kDa protein (Fan et al., 2003; Mou et al., 2013; Liu et al., 2013).

In this study, we identified six DAPs participated in photosynthesis, including TLP, two PSI-E2s, PSRP4, LHCI, and CA, which had reduced abundance levels in response to phytoplasma infection.

In the phytoplasma-infected seedlings, we detected one DAP, PSRP 4 was down regulated, which belongs to photosystem II. Tiller et al. (2012) reported that Arabidopsis RNAi PSRP 4 mutant appeared light-green phenotype, smaller mesophyll cells, and the chlorophyll content, chloroplast translation, plastocyanin content, and maximum quantum efficiency of photosystem II $\left(\mathrm{F}_{\mathrm{V}} / \mathrm{F}_{\mathrm{M}}\right)$ significantly reduced, and the mutants also showed strongly reduced accumulation of three complexes (photosystem II, cytochrome b6f complex, photosystem I), which were responsible for photosynthetic electron transport.

There were three DAPs belong to Photosystem I (PSI), including TLP, LHCI, and PSI-E2. It is well known that thylakoid lumens in both integral and soluble membrane proteins, and TLP take part in light harvesting and electron transfer in the 


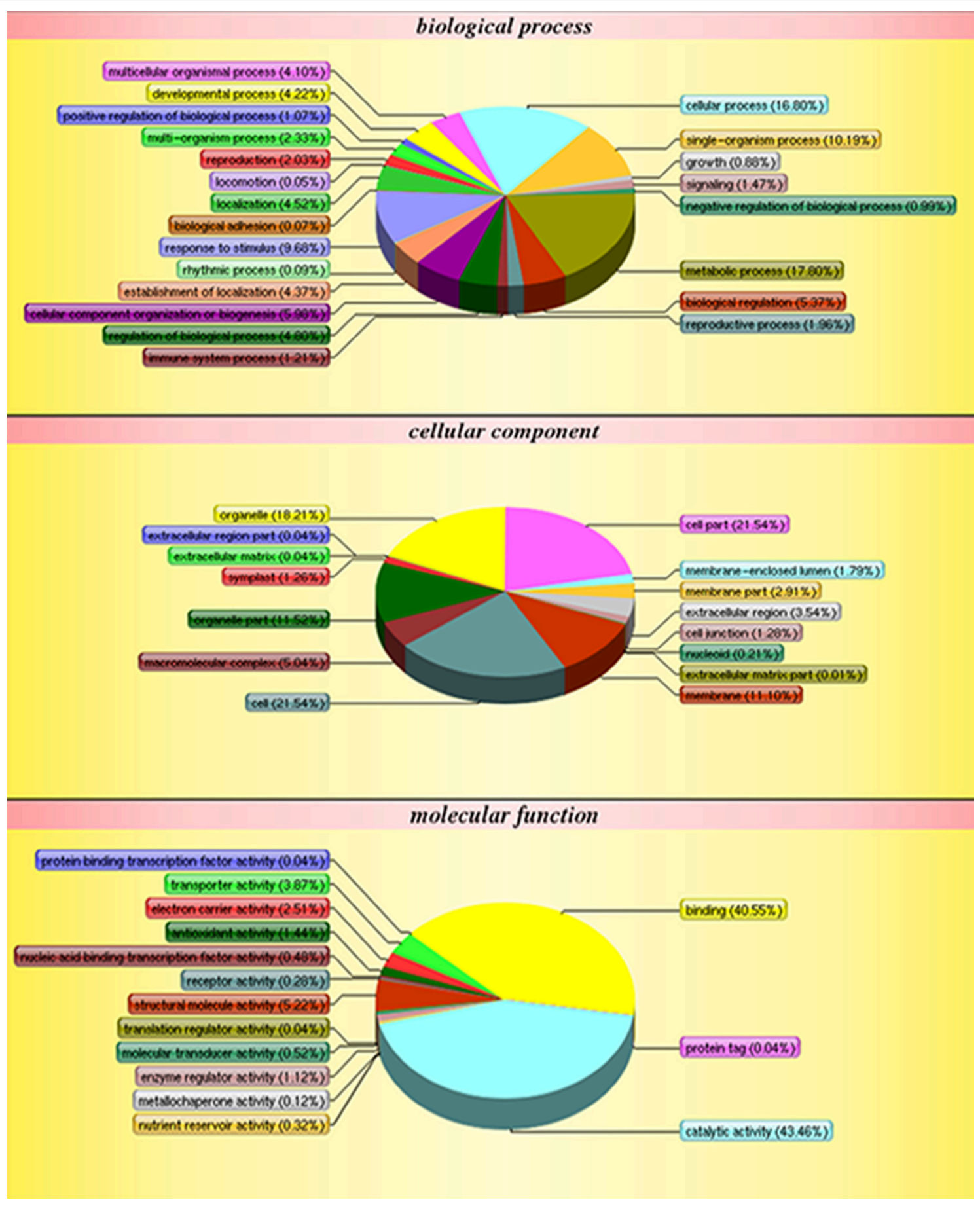

FIGURE 4 | GO classification of all protein.

photosynthetic chain. In this study, the TLP was down-regulated in the diseased seedlings. Evidences showed that the reduction of TLP not only damaged the thylakoid electron flow, but also decreased chlorophyll a content and further slacked the photosynthesis (Wang et al., 2016; Zhu, 2016), this result is consistent with the previous RNA-seq results, which showed that a reduction in photosynthesis of phytoplasma-infected plants could be attributed to the loss of several thylakoid membrane proteins (Mou et al., 2013). At the same time, the expression of LHCI was reduced, which severely affected the light reactions in Photosystem I (PSI) (Bressan et al., 2016). Interestingly, we also detected a decreased abundance of PSI-E2. Ihnatowicz 
TABLE 2 | The number of differently abundance proteins.

\begin{tabular}{|c|c|c|c|}
\hline Comparations & Numbers of up-regulated proteins & Numbers of down-regulated proteins & Numbers of differently abundance proteins \\
\hline PIP vs.PIP-20 & 121 & 157 & 278 \\
\hline PIP-20 vs.PIP-60 & 105 & 99 & 204 \\
\hline HP vs.PIP-60 & 85 & 89 & 174 \\
\hline HP vs.PIP & 122 & 101 & 223 \\
\hline
\end{tabular}

TABLE 3 | Correlation analysis of transcription and proteome.

\begin{tabular}{llcc}
\hline Comparation & Type & $\begin{array}{c}\text { Numbers of } \\
\text { proteins }\end{array}$ & $\begin{array}{c}\text { Numbers of } \\
\text { genes }\end{array}$ \\
\hline PIP vs.PIP-20 & The correlated proteins & 2,050 & 104,021 \\
& Quantitation & 1,046 & - \\
& Differential expression & 278 & 5,461 \\
PIP-20 vs.PIP-60 & The correlated proteins & 2,048 & 105,420 \\
& Quantitation & 1,051 & - \\
& Differential expression & 204 & 18,769 \\
HP vs.PIP-60 & The correlated proteins & 2,049 & 105,217 \\
& Quantitation & 1,083 & - \\
& Differential expression & 174 & 21393 \\
HP vs.PIP & The correlated proteins & 2,051 & 102,661 \\
& Quantitation & 1,073 & - \\
& Differential expression & 223 & 2,821 \\
\hline
\end{tabular}

et al. (2007) demonstrated that the rate of thylakoid electron transfer were not affected in the absence of PSI-E2. Therefore, we speculate that the decreased abundance of the thylakoid lumenal protein in the PaWB-infected $P$. tomentosa plants might partly explain the yellowish leaves symptom.

Another DAP associated with photosynthesis was CA, which had reduced abundance level in the phytoplasma-infected seedlings. This protein plays a vital role in the early event of photosynthesis. Zhurikova et al. (2016) indicated that the reduction of the activity of $\mathrm{CA}$ affected the effective quantum yield of photosystem II, thus, its low abundance might weaken photosynthesis in the phytoplasma-infected plants.

\section{Phytoplasma Infection Induced the Expression of Proteins Related to Dwarf Symptom}

The hormonal imbalance in plants is the most factors for the abnormal symptom. Hoshi et al. (2009) discovered that TENGU can interfere the expression of auxin-related gene, which was the main reason for the plant proliferation and dwarf symptom. In the interaction of paulownia and phytoplasma, Mou et al. (2013) indicated that the key enzymes of cytokinin biosynthesis including isopentenyl diphosphate isomerase and isopentenyltransferase were significantly induced in the phytoplasma-infected Paulownia; Liu et al. (2013) demonstrated that the auxin efflux carrier 5NG4 were downregulated in the phytoplasma-infected seedlings, which resulted in auxin accumulation in the paulownia.
In our proteome analysis, the abundance of two proteins that related to gibberellin (GA) and brassinosteroid (BR) were changed after phytoplasma infection: for example, the abundance of the glycine rich protein GRP was increased in phytoplasma-infected seedlings. It has been shown that overabundance of GRP reduced the activity of several intermediates of the GA biosynthetic pathway, and transgenic Arabidopsis (AtGRP) displayed reduced length of the vegetative stem (Löhr et al., 2014). The abundance of the membrane steroid binding protein (MSBP) also increased after phytoplasma infection. MSBP encodes a 220 -amino acid protein that can bind to 24-epi-brassinolide and negatively regulates BR signaling, and overexpression of MSBP could inhibit cell elongation through downregulating cell elongation related genes, and result in the reduced cell elongation and shortened hypocotyl (Yang et al., 2005). Based on the results above, we concluded that the differentially abundant GRP and MSBP affected GA and BR biosynthesis, which were linked to the short internodes and dwarf morphology.

\section{Phytoplasma Infection Disturb the Energy Metabolism Balance of the Host}

Phytoplasma genomes lack many metabolic pathways, making them unlikely to synthesize nucleotides, and they lack the key gene for ATP synthesis, they may need to import ATP from their host (Carle et al., 2011). Therefore, in phytoplasmainfected plants, the host must supply enough energy for intense phytoplasma growth. In phytoplasma-infected mulberry, the host's energy production was decreased (Ji et al., 2009). Oshima et al. (2001) demonstrated that, in onion, phytoplasma strongly depended on the host's glycolysis pathway to obtain more energy, while, in phytoplasma-infected Mexican lime, energy production by the TCA cycle was significantly enhanced (Monavarfeshani et al., 2013).

In this study, we observed that the abundance levels of some key proteins related to energy metabolism in the phytoplasma-infected $P$. tomentosa, such as ATP synthase gamma subunit, NADP-ME, and GAPC. In the phytoplasmainfected $P$. tomentosa plants, the ATP synthase $\gamma$ subunit showed increased abundance. The ATP synthase $\gamma$ subunit is closely related to the ATP production, and the up-regulation of ATP synthase $\gamma$ subunit can enhance the photosynthetic rates in stressed plant (Budak et al., 2013). It is well known that the activity of chloroplast CF0-CF1-ATP synthase can be regulated by the light-dark. Kohzuma found that the modified $\gamma$ subunit by mutating conserved D211V, E212L, and 226L acidic amino acids only altered the light induced regulation, but not metabolism 
TABLE 4 | List of identified and characterized PaWB related to proteins in other species.

\begin{tabular}{|c|c|c|c|c|c|}
\hline Accession & HP vs. PIP & Annotation & Gene resources & Function classification & References \\
\hline CL51.Contig1_All & Up & $20 S$ proteasome beta subunit & Arabidopsis & $\begin{array}{l}\text { Post-translational modification, } \\
\text { protein turnover, chaperones }\end{array}$ & Dielen et al., 2011 \\
\hline CL2295.Contig5_All & Up & Ubiquitin extension protein & Jatropha & $\begin{array}{l}\text { Post-translational modification, } \\
\text { protein turnover, chaperones }\end{array}$ & Tao et al., 2015 \\
\hline CL6965.Contig2_All & Up & Subunit of chloroplasts chaperonins & Arabidopsis, & $\begin{array}{l}\text { Post-translational modification, } \\
\text { protein turnover, chaperones }\end{array}$ & Zhang et al., 2016 \\
\hline CL9610.Contig1_All & Up & Peptidyl-Prolyl Isomerase & Arabidopsis, & $\begin{array}{l}\text { Post-translational modification, } \\
\text { protein turnover, chaperones }\end{array}$ & Bissoli et al., 2012 \\
\hline CL1409.Contig1_All & Up & Protein grpE & Arabidopsis & $\begin{array}{l}\text { Post-translational modification, } \\
\text { protein turnover, chaperones }\end{array}$ & Hu et al., 2012 \\
\hline CL5562.Contig2_All & Up & fk506- and rapamycin-binding protein & Arabidopsis, & $\begin{array}{l}\text { Post-translational modification, } \\
\text { protein turnover, chaperones }\end{array}$ & $\begin{array}{l}\text { Xiong and Sheen, } \\
2012\end{array}$ \\
\hline CL9305.Contig3_All & Down & $\begin{array}{l}\text { Component of the light harvesting } \\
\text { complex }\end{array}$ & Arabidopsis & Photosynthesis & $\begin{array}{l}\text { Bressan et al., } \\
2016\end{array}$ \\
\hline Unigene11985_All & Down & Chloroplast thylakoid lumen protein & Arabidopsis & Photosynthesis & $\begin{array}{l}\text { Wang et al., 2016; } \\
\text { Zhu, } 2016\end{array}$ \\
\hline CL13475.Contig1_All & Down & Photosystem I subunit E-2 & Arabidopsis & Photosynthesis & $\begin{array}{l}\text { Ihnatowicz et al., } \\
2007\end{array}$ \\
\hline Unigene12214_All & Down & Alpha carbonic anhydrase & Arabidopsis & Photosynthesis & $\begin{array}{l}\text { Zhurikova et al., } \\
2016\end{array}$ \\
\hline CL13475.Contig2_All & Down & Subunit E of photosystem I & Arabidopsis & Photosynthesis & $\begin{array}{l}\text { Ihnatowicz et al., } \\
2007\end{array}$ \\
\hline CL8582.Contig1_All & Down & Plastid-specific ribosomal protein 4 & Arabidopsis & Photosynthesis & Tiller et al., 2012 \\
\hline CL12525.Contig1_All & Up & Ca2+-binding protein & Arabidopsis & Cell signal transduction & Zhou et al., 2013 \\
\hline Unigene12188_All & Up & Ca2+-binding protein & Arabidopsis & Cell signal transduction & Zhou et al., 2013 \\
\hline CL473.Contig1_All & Up & ATP synthase gamma subunit & Arabidopsis & Energy metabolism & Budak et al., 2013 \\
\hline CL13354.Contig2_All & Down & NADP-malic enzyme & Arabidopsis & Energy metabolism & $\begin{array}{l}\text { Tronconi et al., } \\
2008\end{array}$ \\
\hline Unigene11563_All & Up & $\begin{array}{l}\text { Subunit of } \\
\text { glyceraldehyde-3-phosphate } \\
\text { dehydrogenase }\end{array}$ & Arabidopsis & Energy metabolism & Guo et al., 2014 \\
\hline Unigene22259_All & Up & Pectin methylesterase & Arabidopsis & Plant defense & Bethke et al., 2014 \\
\hline CL13450.Contig1_All & Up & Aldo/keto reductase & Jatropha, rice & Plant defense & $\begin{array}{l}\text { Mudalkar et al., } \\
2016\end{array}$ \\
\hline Unigene29082_All & Up & Cinnamyl-alcohol dehydrogenase & Medicago & Plant defense & Zhao et al., 2013 \\
\hline CL3972.Contig3_All & Up & Fasciclin-like arabinogalactan protein & Populus, & Plant defense & $\begin{array}{l}\text { Wang H. et al., } \\
2015\end{array}$ \\
\hline CL7387.Contig1_All & Up & Germin-like protein & Arabidopsis & Plant defense & $\begin{array}{l}\text { Beracochea et al., } \\
2015\end{array}$ \\
\hline CL8516.Contig2_All & Up & Protein tyrosine phosphatases & Rice & $\begin{array}{l}\text { Carbohydrate transport and } \\
\text { metabolism }\end{array}$ & Singh et al., 2010 \\
\hline CL8015.Contig1_All & Up & $\begin{array}{l}\text { Glycerophosphoryl diester } \\
\text { phosphodiesterase-like protein }\end{array}$ & Arabidopsis & Glycerol metabolism & $\begin{array}{l}\text { Hayashi et al., } \\
2008\end{array}$ \\
\hline CL12982.Contig1_All & Up & Disulfide isomerase-like protein & Arabidopsis & Cell redox homeostasis & $\begin{array}{l}\text { Wittenberg et al., } \\
2014\end{array}$ \\
\hline CL9983.Contig2_All & Up & GDSL-motif esterase & Arabidopsis & Carboxylic ester hydrolase & Meyer et al., 2012 \\
\hline Unigene32404_All & Up & Plastid-lipid associated protein & Arabidopsis & $\begin{array}{l}\text { Abscisic acid-mediated } \\
\text { photoprotection }\end{array}$ & $\begin{array}{l}\text { Youssef et al., } \\
2010\end{array}$ \\
\hline CL399.Contig1_All & Up & Subunit of magnesium chelatase & Barley & Coenzyme transport and metabolism & $\begin{array}{l}\text { Braumann et al., } \\
2014\end{array}$ \\
\hline CL4384.Contig3_All & Up & Ubiquitin-fold modifier 1-like isoform & Arabidopsis & $\begin{array}{l}\text { Phosphatidylinositol biosynthetic } \\
\text { process }\end{array}$ & $\begin{array}{l}\text { Paula and } \\
\text { Williams, } 2016\end{array}$ \\
\hline CL4374.Contig1_All & Up & Rubisco small subunit & Arabidopsis & Photorespiration & Ido et al., 2015 \\
\hline Unigene18956_All & Up & Rubisco small subunit & Arabidopsis & Photorespiration & Ido et al., 2015 \\
\hline CL3902.Contig3_All & Down & Plasma membrane $\mathrm{H}+$-ATPase & Arabidopsis & $\begin{array}{l}\text { Inorganic ion transport and } \\
\text { metabolism }\end{array}$ & $\begin{array}{l}\text { Yamauchi et al., } \\
2016\end{array}$ \\
\hline
\end{tabular}


TABLE 4 | Continued

\begin{tabular}{|c|c|c|c|c|c|}
\hline Accession & HP vs. PIP & Annotation & Gene resources & Function classification & References \\
\hline CL13468.Contig1_All & Down & Lipid-transfer protein-like protein & Arabidopsis & Lipid transport & $\begin{array}{l}\text { Edstam and } \\
\text { Edqvist, } 2014\end{array}$ \\
\hline CL11604.Contig1_All & Up & $\begin{array}{l}\text { Acetyl-CoA carboxylase BCCP } \\
\text { subunit }\end{array}$ & Arabidopsis & Fatty acid biosynthesis & Salie et al., 2016 \\
\hline Unigene764_All & Up & Glycine-rich RNA-binding protein & Arabidopsis & General function prediction & Yang et al., 2014 \\
\hline CL4020.Contig3_All & Up & A linker histone like protein & Saccharomyces & DNA binding & $\begin{array}{l}\text { Georgieva et al., } \\
2015\end{array}$ \\
\hline CL6642.Contig1_All & Up & Ribosomal protein L6 family protein & Escherichia coli & $\begin{array}{l}\text { Translation, ribosomal structure and } \\
\text { biogenesis }\end{array}$ & $\begin{array}{l}\text { Shigeno et al., } \\
2016\end{array}$ \\
\hline Unigene4318_All & Up & Histone $\mathrm{H} 2 \mathrm{~A}$ & Arabidopsis & Chromatin structure and dynamics & $\begin{array}{l}\text { Yelagandula et al., } \\
2014\end{array}$ \\
\hline CL6457.Contig2_All & Up & Enhancer of sos3-1 & Tobacco & rRNA processing & Li et al., 2013 \\
\hline Unigene10439_All & Up & $\begin{array}{l}\text { Membrane-associated progesterone } \\
\text { binding protein } 2\end{array}$ & Arabidopsis & Steroid binding & Yang et al., 2005 \\
\hline Unigene21155_All & Up & Unknown/hypothetical & ---- & Unknown/hypothetical & ---- \\
\hline CL5467.Contig1_All & Up & Unknown/hypothetical & ---- & Unknown/hypothetical & ---- \\
\hline CL13502.Contig1_All & Up & Unknown/hypothetical & ---- & Unknown/hypothetical & ---- \\
\hline
\end{tabular}

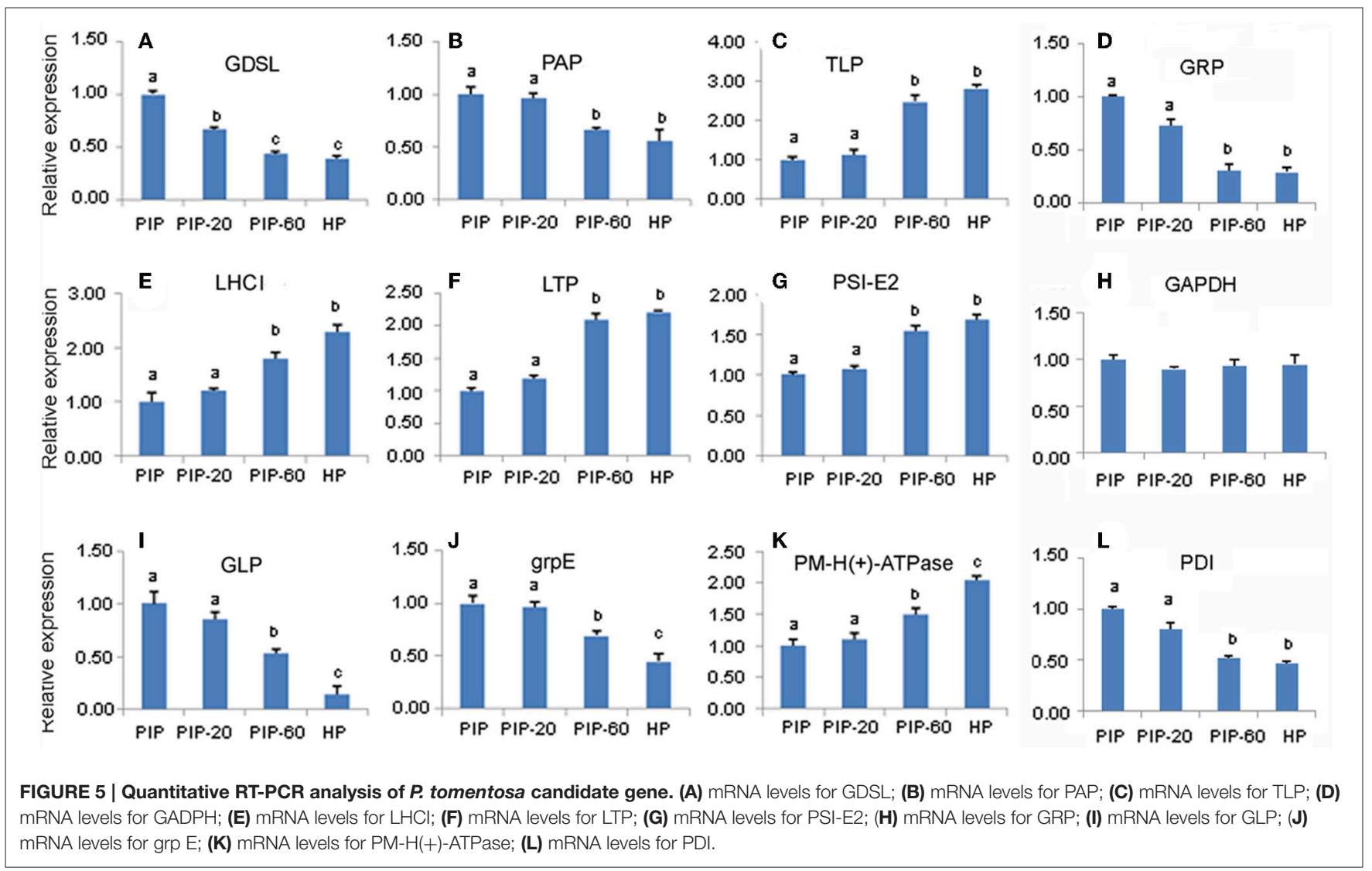

induced regulation, and verified the function mutants of $\gamma$ subunits affected photosynthetic ATP synthesis (Kohzuma et al., 2012, 2013). Therefore, in the photosynthesis pathway, the infected paulownia ATP might exhibit a tendency of increasing.

The other pathway of energy production is TCA cycle, an important pathway of energy production, in our study, the expression of DAP like NADP-ME showed decreased abundance, which plays a central role in the metabolite flux through the TCA cycle. In the Arabidopsis nadp-me knockout mutant, the contents of the TCA metabolites like 2-oxoglutarate and succinate were increased, while that of citrate and fumarate were decreased (Tronconi et al., 2008), implying that differential 
expression of NADP-ME had little impact on TCA cycle, and energy production by TCA cycle was not the necessary pathway for phytoplasma propagation in the host. This result was in disagreement with that in phytoplasma-infected Mexican lime (Monavarfeshani et al., 2013), the difference may be depend on the type of phytoplasmas and their hosts.

Another pathway of energy production is glycolytic pathway. GAPC, an important cytosolic enzyme which catalyzes a key reaction in glycolysis, was up-regulated in the phytoplasma infected seedlings. Evidence showed that GAPC play important roles in energy and carbohydrate metabolites, and Guo et al. (2014) reported that knockout or overexpression of GAPCs caused significantly changes in the content of intermediates of glycolytic pathway, the ratios of ATP/ADP, and $\mathrm{NAD}(\mathrm{P}) \mathrm{H} / \mathrm{NAD}(\mathrm{P})$.

Compared with the DAPs functions of the three energy production pathways above, we supposed that glycolytic and photosynthesis may be the main energy provider for Paulownia response to the phytoplasma. However, details of the actual process need to be further researched.

\section{Phytoplasma Infection Evokes Complicated Cell Signal Transduction Pathways in the Host}

The involvement of cell signal transduction pathways in plant-pathogen interactions directly or indirectly affected plant development (Ranjan et al., 2015). In Paulowniaphytoplasma interactions, many cell signal-related proteins have been identified from the transcriptome level, including plant hormones, calcium-dependent protein kinases, MAP kinases, receptor-like kinases, LRR receptor-like serine/threonine-protein kinases, L-ascorbate peroxidase, (S)-2-hydroxy-acid oxidase, and nitricoxide synthase (Mou et al., 2013; Liu et al., 2013; Cao et al., 2014a,b; Fan et al., 2015b). In our proteome analysis, we detected several DAPs mainly involved in $\mathrm{Ca}^{2+}$, ROS and plant defense signal pathway.

Calcium, an ubiquitous secondary messenger, plays an important role in all aspects of cell function, which has been regarded as versatile intracellular signal (Steinhorst and Kudla, 2014). Calcium-binding proteins is the component of the calcium-signaling pathway. In this study, two $\mathrm{Ca}^{2+}$-binding proteins were increased after phytoplasma infection. Zhou et al. (2013) reported that pathogen can manipulate the host $\mathrm{Ca}^{2+}$ signaling machinery to benefit their own life cycles. At the same time, evidence also has been documented that the calciumbinding protein could be as an effector taking part in plant defense (Ye et al., 2017), demonstrating that calcium-signaling pathway plays a central role in the interaction of paulownia and phytoplasma.

The abundance of the germin-like protein GLP, which belongs to a large ubiquitous family of plant glycoproteins, was also increased in the PaWB-infected seedlings. GLP plays a vital role in plant defense (Rietz et al., 2012). Further, it has been reported that high levels of GLP may initiate oxidative bursts in pathogeninfected plants and elevate the levels of endogenous reactive oxygen species (ROS) (Beracochea et al., 2015). Increasing evidence has shown that ROS (and redox signals) not only can induce cell damage, but also can act as reactive substrates to kill pathogens (Nejat et al., 2015). However, the ROS production was regulated by antioxidant protein disulfide isomerase (PDI), which was induced after phytoplasma infection. PDI, a major ER protein, usually acts as a molecular chaperone and component of signal-transduction pathways. It has been reported that PDI can limit potential cell damage by ROS generation after pathogen infection in plants (Stolf et al., 2011), which has been implicated in the complex interplay of defense-related signaling pathways.

Keeping the above views in mind, our results indicate that the response of $P$. tomentosa to $\mathrm{PaWB}$ infection involved several interconnected signaling pathways, including $\mathrm{Ca}^{2+}$ and ROS-mediated signaling, and plant defense signaling, which coordinate the plant's response to phytoplasma. Regulation of cell signal pathways need different proteins that are induced by interactions with susceptible as well as resistant hosts, which play positive or negative roles in the Paulownia response to phytoplasma, depending on the speed and intensity of the interaction responses.

\section{CONCLUSIONS}

In this study, we combined transcription and proteome analyses to investigate changes in protein abundances in $P$. tomentosa plants in response to phytoplasma infection. The results revealed complex interactions between the Paulownia plants and the phytoplasma, which will contribute substantially to our understanding of the still largely unknown mechanisms that underlie the pathogenicity of phytoplasma. By analyzing the data, we obtained 2,051 proteins, 879 of which were differentially abundant, and 43 of them were found to be related to PaWB. Most of these proteins were predicted to participate in photosynthesis, energy production, and cell signal pathways. Based on the functional analysis of DAPs, we concluded that PaWB infection might lead to decreased photosynthesis, induced the expression of proteins related to dwarf symptom, unbalanced host energy metabolism, as well as abnormalities in cell signal transduction. Together, our data contribute to better understanding the mechanisms associated with PaWB. Future challenges will be to validate the roles of individual proteins and explore their functions in the regulation of the Paulownia response to phytoplasma.

\section{ETHICS STATEMENT}

This article does not contain any studies with human participants or animals performed by any of the authors.

\section{AVAILABILITY OF SUPPORTING DATA}

All sequencing data generated in this study is available from the SRA-Archive (http://www.ncbi.nlm.nih.gov/sra) under the study accession SRP057771 and SRP068599. The 4 cDNA libraries SRA accession number are as follows: SRS924899 (HP), SRS924915 (PIP), SRS1252326 (PIP-20) and SRS924916 (PIP-60). 


\section{AUTHOR CONTRIBUTIONS}

GF conceived and designed the experiments. XC wrote the paper. YD and WL analyzed the data. ZZ performed the experiments. $\mathrm{MD}$ and $\mathrm{ZW}$ contributed reagents and analysis tools.

\section{FUNDING}

This work was supported by the fund of the Transformation Project of the National Agricultural Scientific and Technological Achievement of China (2012GB2D000271), the Central Financial Forestry Science Promotion Project (GTH [2012]01), the Fund of the Technology Innovation Team Project of Zhengzhou (121PCXTD515) and the Fund of Zhongyuan Scholarship Foundation of Henan Province (122101110700).

\section{REFERENCES}

Baggerman, G., Vierstraete, E., De Loof, A., and Schoofs, L. (2005). Gel-based versus gel-free proteomics: a review. Comb. Chem. High. Throughput Screen. 8, 669-677. doi: 10.2174/138620705774962490

Beracochea, V. C., Almasia, N. I., Peluffo, L., Nahirñak, V., Hopp, E. H., Paniego, N., et al. (2015). Sunflower germin-like protein HaGLP1 promotes ROS accumulation and enhances protection against fungal pathogens in transgenic Arabidopsis thaliana. Plant Cell Rep. 34, 1717-1733. doi: 10.1007/s00299-015-1819-4

Bethke, G., Grundman, R. E., Sreekanta, S., Truman, W., Katagiri, F., Glazebrook, J., et al. (2014). Arabidopsis pectin methylesterases contribute to immunity against Pseudomonas syringae. Plant Physiol. 164, 1093-1107. doi: $10.1104 /$ pp.113.227637

Bissoli, G., Niñoles, R. Fresquet, S., Palombieri, S., Palombieri, S., Bueso, E., et al. (2012). Peptidyl-prolyl cis-trans, isomerase ROF2 modulates intracellular $\mathrm{pH}$ homeostasis in Arabidopsis. Plant J. 70, 704-716. doi: 10.1111/j.1365-313X.2012.04921.x

Braumann, I., Stein, N., and Hansson, M. (2014). Reduced chlorophyll biosynthesis in heterozygous barley magnesium chelatase mutants. Plant Physiol.Biochem. 78, 10-14. doi: 10.1016/j.plaphy.2014.02.004

Bressan, M., Dall'Osto, L., Bargigia, I., Alcocer, M. J., Viola, D., Cerullo, G., et al. (2016). LHCII can substitute for LHCI as an antenna for photosystem I but with reduced light-harvesting capacity. Nat. Plants 2:16131. doi: 10.1038/nplants.2016.131

Budak, H., Akpinar, B. A., Unver, T., and Turktas, M. (2013). Proteome changes in wild and modern wheat leaves upon drought stress by twodimensional electrophoresis and nanoLC-ESI-MS/MS. Plant Mol. Biol. 83, 89-103. doi: 10.1007/s11103-013-0024-5

Cao, X., Fan, G., Deng, M., Zhao, Z., and Dong, Y. (2014a). Identification of genes related to Paulownia witches' broom by AFLP and MSAP. Int. J. Mol. Sci. 15, 14669-14683. doi: 10.3390/ijms150814669

Cao, X., Fan, G., Zhao, Z., Deng, M., and Dong, Y. (2014b). Morphological changes of Paulownia seedlings infected phytoplasmasreveal the genes associated with witches' broom through AFLP and MSAP. PLoS ONE 9:e112533. doi: 10.1371/journal.pone.0112533

Carle, P., Malembicmaher, S., Arricaubouvery, N., Desqué, D., Eveillard, S., Carrère, S., et al. (2011). "Flavescence dorée" phytoplasma genome: a metabolism oriented towards glycolysis and protein degradation. Bull. Insectol. 64, S13-S14.

Dadakova, K., Havelkova, M., Kurkova, B., Tlolkova, I., Kasparovsky, T., Zdrahal, Z., et al. (2015). Proteome and transcript analysis of Vitis vinifera cell cultures subjected to Botrytis cinerea infection. J. Proteomics 119, 143-153. doi: 10.1016/j.jprot.2015.02.001

Dielen, A. S., Sassaki, F. T., Walter, J., Michon, T., Ménard, G., Pagny, G., et al. (2011). The $20 \mathrm{~S}$ proteasome $\alpha 5$ subunit of Arabidopsis thaliana carries an RNase activity and interacts in planta with the lettuce mosaic potyvirus

\section{ACKNOWLEDGMENTS}

We thank Edanz China for his assistance with the language proofing and helpful suggestions regarding other issues with the manuscript. We also thank Beijing Genomics Institute-Shenzhen (BGI-Shenzhen) for helping us with the throughput RNA-seq and iTRAQ analysis.

\section{SUPPLEMENTARY MATERIAL}

The Supplementary Material for this article can be found online at: http://journal.frontiersin.org/article/10.3389/fpls.2017. 00342/full\#supplementary-material

HcPro protein. Mol. Plant Pathol. 12, 137-150. doi: 10.1111/j.1364-3703.2010 00654.x

Doi, Y., Ternaka, M., Yora, K., and Asuyama, H. (1967). Mycoplasma or PLT-group-like microorganisms found in the phloem elements of plants infected with mulberry dwarf, potato witches' broom, aster yellows and Paulownia witches' broom. Jpn. J. Phytopathol. 33, 259-266. doi: $10.3186 /$ jjphytopath.33.259

Edstam, M. M., and Edqvist, J. (2014). Involvement of GPI-anchored lipid transfer proteins in the development of seed coats and pollen in Arabidopsis thaliana. Physiol. Plant. 152, 32-42. doi: 10.1111/ppl.12156

Fan, G., Cao, X., Niu, S., Deng, M., Zhao, Z., and Dong, Y. (2015a). Transcriptome, microRNA, and degradome analyses of the gene expression of Paulownia with phytoplamsa. Bmc Genomics 16:896. doi: 10.1186/s12864-0152074-3

Fan, G., Cao, X., Zhao, Z., and Deng, M. (2015b). Transcriptome analysis of the genes related to the morphological changes of Paulownia tomentosa plantlets infected with phytoplasma. Acta Physiol. Plant 37, 1-12. doi: 10.1007/s11738-015-1948-y

Fan, G., Dong, Y., Deng, M., Zhao, Z., Niu, S., and Xu, E. (2014). Plant-pathogen interaction, circadian rhythm, and hormone-related gene expression provide indicators of phytoplasma infection in Paulownia fortunei. Int. J. Mol. Sci. 15, 23141-23162. doi: 10.3390/ijms151223141

Fan, G., and Jiang, J. (1997). Study on the relation between witches' broom, protein and amino acid change in Paulownia leaves. Forest Res. 10, 570-573.

Fan, G., Li, Y., Zheng, J. W., and Zhai, X. Q. (2003). SDS-PAGE of proteins related to Paulownia witches' broom. Sci. Silv. Sin. 39,119-122.

Fan, G., Xu, E., Deng, M., Zhao, Z., and Niu, S. (2015c). Phenylpropanoid metabolism, hormone biosynthesis and signal transduction-related genes play crucial roles in the resistance of Paulownia fortunei to Paulownia witches' broom phytoplasma infection. Genes Genom. 37, 913-929. doi: 10.1007/s13258-015-0321-2

Fan, G., Zhang, S., Zhai, X., Liu, F., and Dong, Z. (2007). Effects of antibiotics on the Paulownia witches' broom phytoplasmas and pathogenic protein related to witches' broom symptom. Sci. Silv. Sin. 43, 138-142.

Fan, J., Chen, C., Yu, Q., Brlansky, R. H., Li, Z. G., Gmitter, F. G., et al. (2011). Comparative iTRAQ proteome and transcriptome analyses of sweet orange infected by "Candidatus Liberibacter asiaticus." Physiol. Plant. 143, 235-245. doi: 10.1111/j.1399-3054.2011.01502.x

Georgieva, M., Staneva, D., Uzunova, K., Efremov, T., Balashev, K., Harata, M., et al. (2015). The linker histone in Saccharomyces cerevisiae interacts with actin-related protein 4 and both regulate chromatin structure and cellular morphology. Int. J. Biochem. Cell B 59, 182-192. doi: 10.1016/j.biocel.2014.12.006

Guo, L., Ma, F., Wei, F., Fanella, B., Allen, D. K., and Wang, X. (2014). Cytosolic phosphorylating glyceraldehyde-3-phosphate dehydrogenases affect Arabidopsis cellular metabolism and promote seed oil accumulation. Plant Cell 26, 3023-3035. doi: 10.1105/tpc.114.126946 
Hayashi, S., Ishii, T., Matsunaga, T., Tominaga, R., Kuromori, T., Wada, T., et al. (2008). The glycerophosphoryl diester phosphodiesterase-like proteins SHV3 and its homologs play important roles in cell wall organization. Plant Cell Physiol. 49, 1522-1535. doi: 10.1093/pcp/pcn120

Hoshi, A., Oshima, K., Kakizawa, S., Ishii, Y., Ozeki, J., Hashimoto, M., et al. (2009). A unique virulence factor for proliferation and dwarfism in plants identified from a phytopathogenic bacterium. Proc. Natl. Acad. Sci.U.S.A. 106, 6416-6421. doi: 10.1073/pnas.0813038106

Hu, C., Lin, S. Y., Chi, W. T., and Charng, Y. Y. (2012). Recent gene duplication and subfunctionalization produced a mitochondrial GrpE, the nucleotide exchange factor of the Hsp70 complex, specialized in thermotolerance to chronic heat stress in Arabidopsis. Plant Physiol. 158, 747-758. doi: 10.1104/pp.111.187674

Ido, A., Iwata, S., Iwata, Y., Igarashi, H., Hamada, T., Sonobe, S., et al. (2015). Arabidopsis Pol II-dependent in vitro transcription system reveals role of chromatin for light-inducible rbcS gene transcription. Plant Physiol. 170, 642-652. doi: 10.1104/pp.15.01614

Ihnatowicz, A., Pesaresi, P., and Leister, D. (2007). The E subunit of photosystem I is not essential for linear electron flow and photoautotrophic growth in Arabidopsis thaliana. Planta 226, 889-895. doi: 10.1007/s00425-007-0534-y

Ji, X., Gai, Y., Zheng, C., and Mu, Z. (2009). Comparative proteomic analysis provides new insights into mulberry dwarf responses in mulberry (Morus alba L.). Proteomics 9, 5328-5339. doi: 10.1002/pmic.200900012

Kohzuma, K., Bosco, C. D., Kanazawa, A., Dhingra, A., Nitschke, W., Meurer, J., et al. (2012). Thioredoxin-insensitive plastid ATP synthase that performs moonlighting functions. Proc. Natl. Acad. Sci. U.S.A. 109, 3293-3298. doi: 10.1073/pnas.1115728109

Kohzuma, K., Dal, B. C., Meurer, J., and Kramer, D. M. (2013). Light and metabolism-related regulation of the chloroplast ATP synthase has distinct mechanisms and functions. J. Biol. Chem. 288, 13156-13163. doi: $10.1074 /$ jbc.m113.453225

Li, D., Ma, N. N., Wang, J. R., Yang, D. Y., Zhao, S. J., and Meng, Q. W. (2013). Overexpression of tomato enhancer of SOS3-1 (LeENH1) in tobacco enhanced salinity tolerance by excluding $\mathrm{Na}+$ from the cytosol. Plant Physiol. Biochem. 70, 150-158. doi: 10.1016/j.plaphy.2013.05.014

Lin, C., Zhou, T., Li, H., Fan, Z., Li, Y., Piao, C., et al. (2009). Molecular characterisation of two plasmids from paulownia witches' broom phytoplasma and detection of a plasmid-encoded protein in infected plants. Eur. J. Plant Pathol. 123, 321-330. doi: 10.1007/s10658-008-9369-z

Liu, R., Dong, Y., Fan, G., Zhao, Z., Deng, M., Cao, X., et al. (2013). Discovery of genes related to witches' broom disease in Paulownia tomentosa $\times$ Paulownia fortunei by a de novo assembled transcriptome. PLOS ONE 8:e80238. doi: 10.1371/journal.pone.0080238

Livak, K. J., and Schmittgen, T. D. (2000). Analysis of relative gene expression data using Real-Time quantitative PCR and the $2^{-\Delta \Delta C}$ T method. Methods 25, 402-408. doi: 10.1006/meth.2001.1262

Lodha, T. D., Hembram, P., Tep, N., and Basak, J. (2013). Proteomics: a successful approach to understand the molecular mechanism of plant-pathogen interaction. Am. J. Plant Sci. 4, 1212-1226. doi: 10.4236/ajps.2013.46149

Löhr, B., Streitner, C., Steffen, A., Lange, T., and Staiger, D. (2014). A glycine-rich RNA-binding protein affects gibberellin biosynthesis in Arabidopsis. Mol. Biol. Rep. 41, 439-445. doi: 10.1007/s11033-013-2878-7

Luge, T., Kube, M., Freiwald, A., Meierhofer, D., Seemüller, E., and Sauer, S. (2014). Transcriptomics assisted proteomic analysis of Nicotiana occidentalis infected by Candidatus Phytoplasma mali strain AT. Proteomics 14, 1882-1889. doi: 10.1002/pmic.201300551

Margaria, P., Abbà, S., and Palmano, S. (2012). Novel aspects of grapevine response to phytoplasma infection investigated by a proteomic and phospho-proteomic approach with data integration into functional networks. BMC Genomics 14:38. doi: 10.1186/1471-2164-14-38

Meng, Q., Hou, L., Zhao, Y., Huang, X., Huang, Y., Xia, S., et al. (2014). iTRAQbased proteomic study of the effects of Spiroplasma eriocheiris on Chinese mitten crab Eriocheir sinensis hemocytes. Fish Shellfish Immun. 40, 182-189. doi: $10.1016 /$ j.fsi.2014.06.029

Meyer, R. C., Wituckawall, H., Becher, M., Blacha, A., Boudichevskaia, A., Dörmann, P., et al. (2012). Heterosis manifestation during early Arabidopsis seedling development is characterized by intermediate gene expression and enhanced metabolic activity in the hybrids. Plant J. 71, 669-683. doi: 10.1111/j.1365-313X.2012.05021.x
Molloy, M. P., and Witzmann, F. A. (2002). Proteomics: technologies and applications. Brief. Funct. Genomic 1, 23-39. doi: 10.1093/bfgp/1.1.23

Monavarfeshani, A., Mirzaei, M., Sarhadi, E., Amirkhani, A., Nekouei, M. K., Haynes, P. A., et al. (2013). Shotgun proteomic analysis of the Mexican Lime tree infected with "Candidatus Phytoplasma aurantifolia." J. Proteome Res. 12, 785-795. doi: 10.1021/pr300865t

Mou, H. Q., Lu, J., Zhu, S. F., Lin, C. L., Tian, G. Z., Xu, X., et al. (2013). Transcriptomic analysis of Paulownia infected by Paulownia witches' broom phytoplasma. PLoS ONE 8:e77217. doi: 10.1371/journal.pone.0077217

Mudalkar, S., Sreeharsha, R. V., and Reddy, A. R. (2016). A novel aldoketo reductase from Jatropha curcas L. (JcAKR) plays a crucial role in the detoxification of methylglyoxal, a potent electrophile. J. Plant Physiol. 195, 39-49. doi: 10.1016/j.jplph.2016.03.005

Murashige, T., and Skoog, F. (1962). A Revised medium for rapid growth and bio assays with tobacco tissue cultures. Physiol. Plant. 15, 473-497. doi: 10.1111/j.1399-3054.1962.tb08052.x

Namba, S. (2002). Molecular biological studies on phytoplasmas. J. Gen. Plant Pathol. 68, 257-259. doi: 10.1007/PL00013086

Nejat, N., Cahill, D. M., Vadamalai, G., Ziemann, M., Rookes, J., and Naderali, N. (2015). Transcriptomics-based analysis using RNA-Seq of the coconut (Cocos nucifera) leaf in response to yellow decline phytoplasma infection. Mol. Gen. Genet. 290, 1899-1910. doi: 10.1007/s00438-015-1046-2

Niu, S., Fan, G., Deng, M., Zhao, Z., Xu, E., and Lin, C. (2016). Discovery of microRNAs and transcript targets related to witches' broom disease in Paulownia fortunei by high-throughput sequencing and degradome approach. Mol. Gen. Genet. 291, 181-191. doi: 10.1007/s00438-015-1102-y

Oshima, K., Shiomi, T., Kuboyama, T., Sawayanagi, T., Nishigawa, H., Kakizawa, S., et al. (2001). Isolation and characterization of derivative lines of the onion yellows phytoplasma that do not cause stunting or phloem hyperplasia. Phytopathology 91, 1024-1029. doi: 10.1094/PHYTO.2001.91.11.1024

Paula, C., and Williams, M. R. (2016). Phenotypic characterization of the Arabidopsis ufm1 (Ubiquitin Fold Modifier) gene involved in seed development. Am. J. Plant Physiol. 12, 10-19. doi: 10.3923/ajpp.2017.10.19

Qiao, J., Wang, J., Chen, L., Tian, X., Huang, S., Ren, X., et al. (2012). Quantitative iTRAQ LC-MS/MS proteomics reveals metabolic responses to biofuel ethanol in Cyanobacterial Synechocystis sp. PCC 6803. J. Proteome Res. 11, 5286-5300. doi: $10.1021 / \mathrm{pr} 300504 \mathrm{w}$

Ranjan, A., Vadassery, J., Patel, H. K., Pandey, A., Palaparthi, R., Mithöfer, A., et al. (2015). Upregulation of jasmonate biosynthesis and jasmonate-responsive genes in rice leaves in response to a bacterial pathogen mimic. Funct. Integr. Genomic. 15, 363-373. doi: 10.1007/s10142-014-0426-8

Rietz, S., Bernsdorff, F. E., and Cai, D. (2012). Members of the germin-like protein family in Brassica napus are candidates for the initiation of an oxidative burst that impedes pathogenesis of Sclerotinia sclerotiorum. J. Exp. Bot. 63, 5507-5519. doi: 10.1093/jxb/ers203

Salie, M. J., Zhang, N., Lancikova, V., Xu, D., and Thelen, J. J. (2016). A family of negative regulators targets the committed step of de novo fatty acid biosynthesis. Plant Cell. 28, 2312-2325. doi: 10.1105/tpc.16.00317

Scarpari, L. M., Meinhardt, L. W., Mazzafera, P., Pomella, A. W. V., Schiavinato, M. A., Cascardo, J. C. M., et al. (2005). Biochemical changes during the development of witches' broom: the most important disease of cocoa in Brazil caused by Crinipellis perniciosa. J. Exp. Bot. 56, 865-877. doi: $10.1093 /$ jxb/eri079

Shigeno, Y., Uchiumi, T., and Nomura, T. (2016). Involvement of ribosomal protein L6 in assembly of functional 50S ribosomal subunit in Escherichia coli cells. Biochem. Biophys. Res. Commun. 473, 237-242. doi: 10.1016/j.bbrc.2016.03.08

Singh, A., Giri, J., Kapoor, S., Tyagi, A., and Pandey, G. (2010). Protein phosphatase complement in rice: genome-wide identification and transcriptional analysis under abiotic stress conditions and reproductive development. BMC Genomics. 11:435. doi: 10.1186/1471-2164-11-435

Steinhorst, L., and Kudla, J. (2014). Signaling in cells and organisms - calcium holds the line. Curr. Opin. Plant Biol. 22, 14. doi: 10.1016/j.pbi.2014.08.003

Stolf, B. S., Smyrnias, I., Lopes, L. R., Vendramin, A., Goto, H., Laurindo, F. R., et al. (2011). Protein disulfide isomerase and host-pathogen interaction. Sci. World J. 11, 1749-1761. doi: 10.1100/2011/289182

Taheri, F., Nematzadeh, G., Zamharir, M. G., Nekouei, M. K., Naghavi, M., Mardi, M., et al. (2011). Proteomic analysis of the Mexican lime tree response to 
"Candidatus Phytoplasma aurantifolia" infection. Mol. Biosyst. 7, 3028-3035. doi: $10.1039 / \mathrm{clmb} 05268 \mathrm{c}$

Tang, Z., Du, W., Du, X. L., Ban, Y. Y., and Cheng, J. L. (2016). iTRAQ protein profiling of adventitious root formation in Mulberry Hardwood Cuttings. J. Plant Growth Regul. 35, 618-631. doi: 10.1007/s00344-015-9567-9

Tao, Y. B., He, L. L., Niu, L. J., and Xu, Z. F. (2015). Isolation and characterization of an ubiquitin extension protein gene (JcUEP) promoter from Jatropha curcas. Planta 241, 823-836. doi: 10.1007/s00425-014-2222-z

Tiller, N., Weingartner, M., Thiele, W., Maximova, E., Schöttler, M. A., and Bock, R. (2012). The plastid-specific ribosomal proteins of Arabidopsis thaliana can be divided into non-essential proteins and genuine ribosomal proteins. Plant J. 69, 302-316. doi: 10.1111/j.1365-313X.2011.04791.x

Tronconi, M. A., Fahnenstich, H., Gerrard Weehler, M. C., Andreo, C. S., Flügge, U. I., Drincovich, M. F., et al. (2008). Arabidopsis NAD-malic enzyme functions as a homodimer and heterodimer and has a major impact on nocturnal metabolism. Plant Physiol. 146, 1540-1552. doi: 10.1104/pp.107.114975

Wang, B., Hajano, J. U. D., Ren, Y., Lu, C., and Wang, X. (2015). iTRAQ-based quantitative proteomics analysis of rice leaves infected by Rice stripe virus reveals several proteins involved in symptom formation. J. Virol. 12, 1-21. doi: 10.1186/s12985-015-0328-y

Wang, H., Jiang, C., Wang, C., Yang, Y., Yang, L., Gao, X., et al. (2015). Antisense expression of the fasciclin-like arabinogalactan protein FLA6 gene in Populus inhibits expression of its homologous genes and alters stem biomechanics and cell wall composition in transgenic trees. J. Exp. Bot. 66, 1291-1302. doi: $10.1093 / \mathrm{jxb} / \mathrm{eru} 479$

Wang, Z., Li, D., Cao, X., Song, C., and Zhou, Y. (2016). Photosynthetic characteristics and inferred changes in thylakoid membrane fluidity determine bloom succession between Anabaena and Microcystis in eutrophic lakes. J. Appl. Phycol. 28, 2353-2365. doi: 10.1007/s10811-015-0786-z

Wittenberg, G., Levitan, A., Klein, T., Dangoor, I., Keren, N., and Danon, A. (2014), Knockdown of the Arabidopsis thaliana chloroplast protein disulfide isomerase 6 results in reduced levels of photoinhibition and increased D1 synthesis in high light. Plant J. 78, 1003-1013. doi: 10.1111/tpj. 12525

Xiong, Y., and Sheen, J. (2012). Rapamycin and glucose-target of rapamycin (TOR) protein signaling in plants. J. Biol. Chem. 287, 2836-2842. doi: 10.1074/jbc.M111.300749

Yamauchi, S., Takemiya, A., Sakamoto, T., Kurata, T., Tsutsumi, T., Kinoshita, T., et al. (2016). The Plasma Membrane $\mathrm{H}^{+}$-ATPase AHA1 plays a major role in stomatal opening in response to blue light. Plant Physiol. 171, 2731-2743. doi: 10.1104/pp.16.01581

Yang, D. H., Kwak, K. J., Min, K. K., Su, J. P., Yang, K. Y., and Kang, H. (2014). Expression of Arabidopsis glycine-rich RNA-binding protein AtGRP2 or AtGRP7 improves grain yield of rice (Oryza sativa) under drought stress conditions. Plant Sci. 214, 106-112. doi: 10.1016/j.plantsci.2013.10.006
Yang, X. H., Xu, Z. H., and Xue, H. W. (2005). Arabidopsis membrane steroid binding protein 1 is involved in inhibition of cell elongation. Plant Cell 17, 116-131. doi: 10.1105/tpc.104.028381

Ye, W., Yu, H., Jian, Y., Zeng, J., Ji, R., Chen, H., et al. (2017). A salivary EFhand calcium-binding protein of the brown planthopper Nilaparvata lugens functions as an effector for defense responses in rice. Sci. Rep. 7:40498. doi: $10.1038 /$ srep 40498

Yelagandula, R., Stroud, H., Holec, S., Zhou, K., Feng, S., Zhong, X., et al. (2014). The histone variant H2A.W defines heterochromatin and promotes chromatin condensation in Arabidopsis. Cell 158, 98-109. doi: 10.1016/j.cell.2014. 06.006

Youssef, A., Laizet, Y. H., Block, M. A., Maréchal, E., Alcaraz, J. P., Larson, T. R., et al. (2010). Plant lipid-associated fibrillin proteins condition jasmonate production under photosynthetic stress. Plant J. 61, 436-445. doi: 10.1111/j.1365-313X.2009.04067.x

Zhang, S., Zhou, H., Feng, Y., Bai, C., Zhao, Q., He, J. H., et al. (2016). Structural insight into the cooperation of chloroplast chaperonin subunits. BMC Biol. 14:29. doi: 10.1186/s12915-016-0251-8

Zhao, Q., Tobimatsu, Y., Zhou, R., Pattathil, S., Gallego-Giraldo, L., Fu, C., et al. (2013). Loss of function of cinnamyl alcohol dehydrogenase 1 leads to unconventional lignin and a temperature-sensitive growth defect in Medicago truncatula. Proc. Natl. Acad. Sci. U.S.A. 110, 13660-13665. doi: $10.1073 /$ pnas. 1312234110

Zhou, Y., Xue, S., and Yang, J. J. (2013). Calciomics: integrative studies of Ca2+binding proteins and their interactomes in biological systems. Metallomics 5, 29-42. doi: 10.1039/C2MT20009K

Zhu, Y. (2016). A Novel Redoxin in the thylakoid membrane regulates the titer of photosystem I. J. Korean Soc. Appl. Biol. 291, 18689-18699. doi: 10.1074/jbc.m116.721175

Zhurikova, E. M., Ignatova, L. K., Rudenko, N. N., Mudrik, V. A., Vetoshkina, D. V., et al. (2016). Participation of two carbonic anhydrases of the alpha family in photosynthetic reactions in Arabidopsis thaliana. Biochemistry 81, 1182. doi: $10.1134 / \mathrm{s} 0006297916100151$

Conflict of Interest Statement: The authors declare that the research was conducted in the absence of any commercial or financial relationships that could be construed as a potential conflict of interest.

Copyright $(02017$ Cao, Fan, Dong, Zhao, Deng, Wang and Liu. This is an open-access article distributed under the terms of the Creative Commons Attribution License (CC $B Y$ ). The use, distribution or reproduction in other forums is permitted, provided the original author(s) or licensor are credited and that the original publication in this journal is cited, in accordance with accepted academic practice. No use, distribution or reproduction is permitted which does not comply with these terms. 